\title{
Potent neuroprotection induced by remote preconditioning in a rat model of neonatal cerebral hypoxic-ischemic injury
}

\author{
Michael B. Tropak, PhD, ${ }^{\mathrm{a}}$ Hui Shi, MD, ${ }^{\mathrm{b}}$ Jing Li, MD, ${ }^{\mathrm{c}}$ XiaoJing Dai, MD, ${ }^{\mathrm{c}}$ \\ Andrew N. Redington, $\mathrm{MD},{ }^{\mathrm{c}}$ and Rand Askalan, $\mathrm{PhD}, \mathrm{MD},{ }^{\mathrm{b}, \mathrm{d}}$ Toronto, Ontario, Canada
}

\begin{abstract}
Although mortality in young children undergoing heart procedures has fallen, awareness of associated late morbidities has risen. For example, although early mortality associated with the arterial switch operation for transposition of the great arteries is now on the order of $1 \%$, late neurocognitive and behavioral problems remain frequent, regardless of whether circulatory arrest or low-flow cardiopulmonary bypass is used. ${ }^{1}$ Consequently, the need for improved perioperative neuroprotective strategies has recently been highlighted as among the most important research imperatives in the treatment of congenital heart disease. ${ }^{2}$

We first demonstrated a potent cardioprotective effect of remote ischemic preconditioning (rIPC), induced by $4 \mathrm{cy}-$ cles of transient (5 minutes) ischemia and reperfusion of the hind limb, in a large animal model of myocardial injury. ${ }^{3}$ This observation was rapidly translated to our first human randomized, controlled trial, which showed that rIPC achieved by limb ischemia (induced simply with a standard blood pressure cuff inflated to suprasystolic levels) leads to reduced markers of myocardial damage, reduced inotrope requirements, and improved lung function in children undergoing repair of congenital heart defects. ${ }^{4}$ Since then, other studies have shown similar benefits for children undergoing heart surgery; however, there have been no assessments of neurocognitive outcomes in these clinical studies.
\end{abstract}

\section{MATERIALS AND METHODS}

To test the hypothesis that rIPC induced by the described method reduces brain injury, we applied the Rice-Vannucci hypoxic-ischemic model ${ }^{5}$ to rat pups on postnatal day 14 (equivalent to 1 -week-old term human neonates). All animal protocols were approved by the Animal Care and Use Committee of the Hospital for Sick Children in Toronto. Pups were anesthetized with isoflurane $(2.5 \%$ of the total intake gas). After random assignment to sham procedure (control) or active treatment, rIPC was induced by 3 cycles of 5 minutes of hind limb ischemia (achieved noninva-

\footnotetext{
From the Program in Genetics and Genome Biology, ${ }^{\mathrm{a}}$ the Program of Neuroscience and Mental Health, ${ }^{\mathrm{b}}$ the Division of Cardiology, Labatt Family Heart Center, ${ }^{\mathrm{c}}$ and the Division of Neurology, ${ }^{\mathrm{d}}$ Hospital for Sick Children, Toronto, Ontario, Canada.

Disclosures: Authors have nothing to disclose with regard to commercial support.

Andrew N. Redington and Rand Askalan contributed equally to the article.

Received for publication Dec 20, 2010; revisions received March 18, 2011; accepted for publication April 6, 2011; available ahead of print May 11, 2011.

Address for reprints: Rand Askalan, PhD, MD, Division of Neurology, Hospital for Sick Children, 555 University Ave, Toronto, ON, Canada M5G 1X 8 (E-mail: rand.askalan@sickkids.ca).

J Thorac Cardiovasc Surg 2011;142:233-5

$0022-5223 / \$ 36.00$

Copyright (c) 2011 by The American Association for Thoracic Surgery doi:10.1016/j.jtcvs.2011.04.003
}

sively with a tourniquet tightened at the inguinal level) followed by 5 minutes of reperfusion as previously described. ${ }^{6}$ Either rIPC or sham intervention was immediately followed by unilateral internal carotid artery ligation and exposure to $8 \%$ hypoxia for approximately 65 minutes to cause a reproducible hypoxic-ischemic damage involving the caudate, putamen, hippocampus, and cortical regions ipsilateral to the ligated carotid. In this model the contralateral hemisphere is largely unaffected, even in control subjects. Brains were removed 1 week after the hypoxic ischemic insult, fixed, embedded in paraffin, and cut into $5-\mu \mathrm{m}$ coronal sections. The total area of brain tissue loss was measured on hematoxylin and eosin-stained sections, and total infarct volume was calculated according to the Cavalieri principle.

\section{RESULTS}

Six of the 16 pups in the sham-treated control group and 5 of the 15 in the rIPC group did not survive the initial procedure. Subsequently, brain samples from each of the surviving rat pups in the control $(\mathrm{n}=10)$ and rIPC treatment $(\mathrm{n}=10)$ groups were assessed for cerebral infarct volume. Infarct area, characterized by the presence of paranchymal vacuolations, acidophilic neurons, and pyknotic nuclei, was reduced in the rIPC group (Figure 1, $B$ and $D$ ) relative to the control group (Figure 1, $A$ and $C$ ). Summation of infarct volume in the 2 groups showed a 3.5 -fold $(71.4 \%)$ decrease in infarct volume in the rIPC group $\left(8.7 \pm 2.7 \mathrm{~mm}^{3}, \mathrm{n}=10\right)$ versus the sham-treated group $\left(30.2 \pm 5.3 \mathrm{~mm}^{3}, \mathrm{n}=10\right.$, $P<.003$ by unpaired $t$ test with the Welch correction; Figure 2).

\section{DISCUSSION}

It has been shown both in animal studies and in recent clinical trials that rIPC invokes potent myocardial protection and as such warrants further investigation as a potential therapeutic intervention to prevent hypoxic-ischemic brain damage in children after heart operations. In this proof-ofprinciple study, we showed in a model of neonatal hypoxicischemic brain injury that rIPC induced by transient ischemia to the hind limb in 14-day-old rat pups significantly $(P=.003)$ reduced cerebral infarct volume by $70 \%$ from $30.4 \pm 5.3 \mathrm{~mm}^{3}$ (control) to $8.7 \pm 2.7 \mathrm{~mm}^{3}$ (rIPC).

This is the first study to show that rIPC induced by repeated transient ischemia to the hind limb reduces cerebral infarct volume in juvenile animals subjected to hypoxic-ischemic injury. The approximately $70 \%$ reduction in infarct volume relative to the sham-treated group observed in this study was at least as potent as the $40 \%$ to $60 \%$ reduction in myocardial infarct size generally shown in studies of cardioprotection by rIPC. It remains to be established whether the mode of neuroprotection is similar to that of 

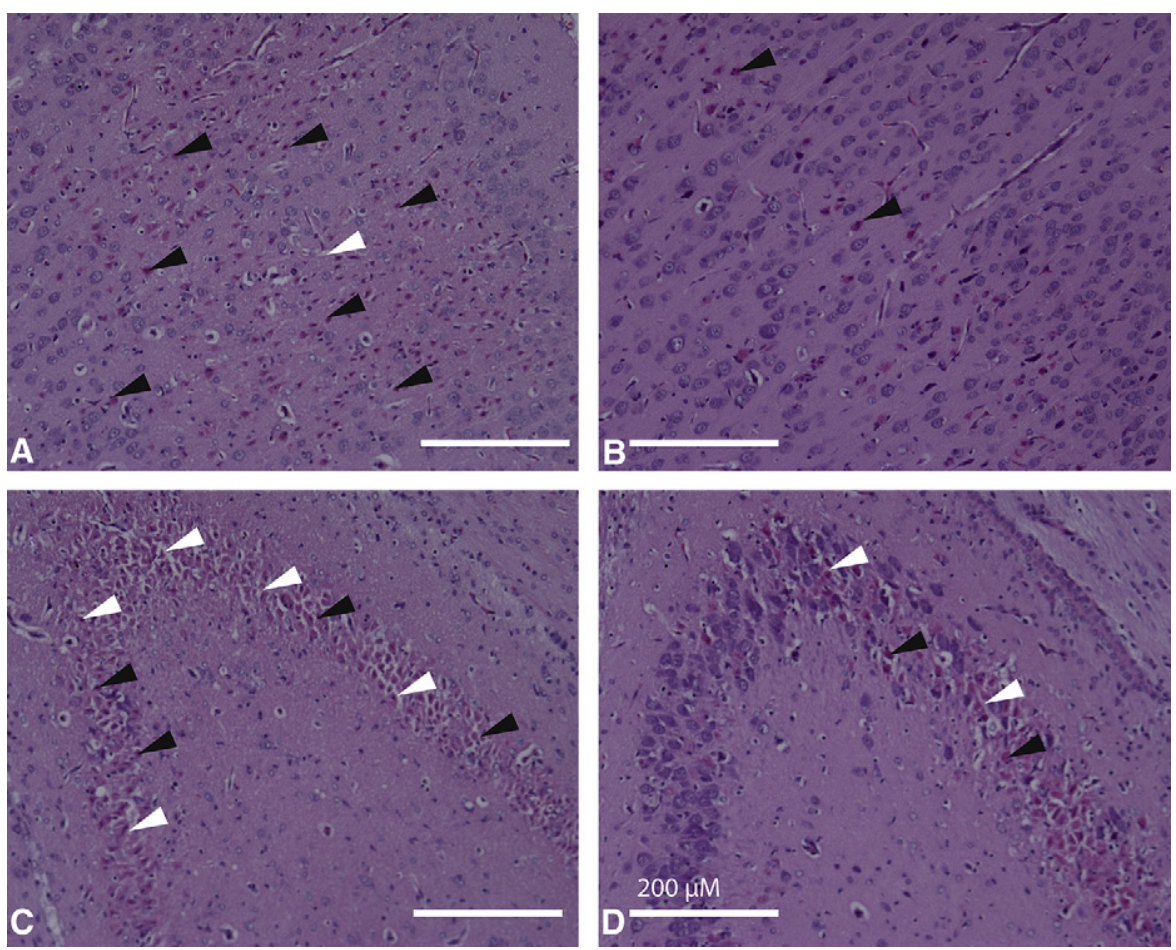

FIGURE 1. Remote ischemic preconditioning reduces infarcted area after unilateral internal carotid artery ligation and hypoxic challenge. Shown are representative infarcted zones in cortical (A and B) and hippocampal (C and D) regions ipsilateral to the arterial ligation. Hematoxylin and eosin-stained sections from sham-treated pups (A and C) contain numerous vaculations (white arrowheads), acidophilic neurons, and pyknotic nuclei (stained pink compared with the normal nuclei that stain blue; black arrowheads) compared with sections from remote ischemic preconditioning-treated pups (B and D).

cardioprotection. If, however, the protective humoral factor that we and others ${ }^{6,7}$ have shown to be released after rIPC is the same that affords neuroprotection, then it must be

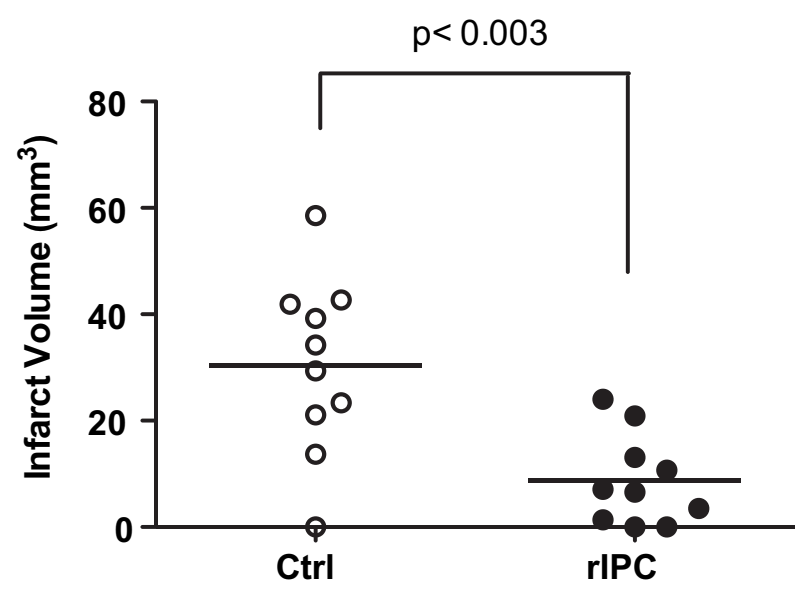

FIGURE 2. Remote ischemic preconditioning reduces cerebral infarct volume after unilateral internal carotid artery ligation and hypoxic challenge. Scatterplot shows cerebral infarct volume (in cubic millimeters) in control (Ctrl, open circles) and remote ischemic preconditioning ( $r I P C$, filled circles) groups. Mean ( \pm SE) infarct volumes for remote ischemic preconditioning group $\left(8.7 \pm 2.7 \mathrm{~mm}^{3}, \mathrm{n}=10\right)$ and control group $\left(30.4 \pm 5.3 \mathrm{~mm}^{3}, \mathrm{n}=10\right)$ were significantly different $(P<.003)$. capable of crossing the blood-brain barrier in some manner. Our previous data show that any factor must be smaller than $15 \mathrm{kDa}$ in size, and a hydrophobic factor would be compatible with such a mechanism. ${ }^{6}$

The need for improved strategies to provide neuroprotection has been highlighted in a recent report from the Pediatric Heart Network and National Heart, Lung, and Blood Institute Working Group on the Perioperative Management of Congenital Heart Disease as among the most important research themes in the field of cardiovascular disease in children. $^{2}$ Perioperative brain damage in these young children is clearly multifactorial, reflecting the effects of hypoxia, ischemia, inflammation, and genetic factors. ${ }^{8}$ If, however, our results were to translate to a similar degree of neuroprotection in clinical trials, rIPC might well represent a readily implementable and efficacious therapeutic option for these vulnerable infants.

\section{References}

1. Bellinger DC, Wypij D, Kuban KC, Rappaport LA, Hickey PR, Wernovsky G, et al. Developmental and neurological status of children at 4 years of age after heart surgery with hypothermic circulatory arrest or low-flow cardiopulmonary bypass. Circulation. 1999;100:526-32.

2. Kaltman JR, Andropoulos DB, Checchia PA, Gaynor JW, Hoffman TM, Laussen PC, et al. Report of the Pediatric Heart Network and National Heart, Lung, and Blood Institute working group on the perioperative management of congenital heart disease. Circulation. 2010;121:2766-72. 
3. Kharbanda RK, Mortensen UM, White PA, Kristiansen SB, Schmidt MR, Hoschtitzky JA, et al. Transient limb ischemia induces remote ischemic preconditioning in vivo. Circulation. 2002;106:2881-3.

4. Cheung MM, Kharbanda RK, Konstantinov IE, Shimizu M, Frndova H, Li J, et al. Randomized controlled trial of the effects of remote ischemic preconditioning on children undergoing cardiac surgery: first clinical application in humans. $J A m$ Coll Cardiol. 2006;47:2277-82.

5. Rice JE 3rd, Vannucci RC, Brierley JB. The influence of immaturity on hypoxicischemic brain damage in the rat. Ann Neurol. 1981;9:131-41.
6. Shimizu M, Tropak M, Diaz RJ, Suto F, Surendra H, Kuzmin E, et al. Transien limb ischaemia remotely preconditions through a humoral mechanism acting directly on the myocardium: evidence suggesting cross-species protection. Clin Sci (Lond). 2009;117:191-200.

7. Lim SY, Yellon DM, Hausenloy DJ. The neural and humoral pathways in remote limb ischemic preconditioning. Basic Res Cardiol. 2010;105:651-5.

8. Fuller S, Nord AS, Gerdes M, Wernovsky G, Jarvik GP, Bernbaum J, et al. Predictors of impaired neurodevelopmental outcomes at one year of age after infant cardiac surgery. Eur J Cardiothorac Surg. 2009;36:40-7. 